\title{
Bait correlation improves interactor identification by Tandem Mass Tag-Affinity Purification-Mass Spectrometry
}

Liangyong Meit,a, Maureen R. Montoya ${ }^{\dagger, a}$, Guy M. Quanruda, Minh Tran ${ }^{a}$, Athena Villa-Sharma ${ }^{a}$, Ming Huang ${ }^{b}$, and Joseph C. Genereux ${ }^{a, b, *}$

\begin{tabular}{ll} 
Page & \multicolumn{1}{c}{ Contents } \\
\hline S1 & Table of Contents \\
S2 & Figure Legends \\
S6 & Figure S1 \\
S11 & Figure S2 \\
S12 & Figure S3 \\
S13 & Figure S5 \\
S14 & Figure S6 \\
S15 & Figure S7 \\
S16 & Supplemental Methods \\
S20 & Table S1 \\
S21 & Table S2 \\
S22 & Table S3 \\
\hline & Table S4, separate excel file \\
\hline S23 & Table S5, separate excel file \\
S24 & Mable S6 \\
\hline
\end{tabular}




\section{FIGURE LEGENDS -}

Figure S1. Box and whisker plots of the distribution of Areas Under the Curve for Receiver Operating Characteristic Curves generated from simulations (100 replicates) of non-specific (non-interactor) and specific (prey) proteins recovered from bait immunoprecipitation. The following conditions were varied (parameter names in parentheses): Bait Levels Sampling Variation (Bait Levels Channel Standard Deviation), Mean Non-specific Levels of Non-interactors (NonSpecific Noninteract Mean), Prey:Bait ratio Variation (Ratio Standard Deviation), Mean Nonspecific Prey Levels (Non-Specific Prey Mean), Variation in Nonspecific Recovery of Noninteractors (Nonspecific Noninteract Standard Deviation), Mean Prey-to-bait Ratio (Ratio Mean), Number of Non-interactors, and Number of Interactors. Parameter values that were varied are indicated for each plot (abscissa) and calculated with a bait level variance (Bait Levels Standard Deviation) set to 0.3. Other parameters are provided in

\section{Table S2.}

\section{Figure S2.}

A. MS2 spectra for ${ }^{F L A G D N A J B 8}{ }^{H 31 Q}$ peptides used for parallel reaction monitoring (PRM). Boxes indicate the fragment peaks that were used for quantification.

B. Representative PRM chromatograms of FLAGDNAJB8 ${ }^{\mathrm{H} 31 \mathrm{Q}}$ peptides.

C. Plot comparing the TMT reporter ion ratios for eluted ${ }^{F L A G D N A J B 8} 8^{\mathrm{H} 31 \mathrm{Q}}$ to the ${ }^{\mathrm{FLAG}}{ }^{\mathrm{D} N A J B 8} 8^{\mathrm{H} 31 \mathrm{Q}}$ levels in the lysates as ascertained by PRM. Cells were transfected with $2 \mu \mathrm{g}, 4 \mu \mathrm{g}$, or $8 \mu \mathrm{g}$ DNA encoding ${ }^{F L A G D N A J B 8}{ }^{\mathrm{H} 31 \mathrm{Q}}$, crosslinked with DSP, quenched, and lysed. Aliquots of lysate were processed for PRM mass spectrometry. The remaining lysate was normalized for total protein and loaded onto M2 anti-FLAG magnetic Dynabeads for immunoprecipitation. Beads 
were washed well with RIPA buffer prior to elution. Eluates were processed for mass spectrometry and labeled with TMT tags. Standard deviations for PRM are across peptides.

D. Representative silver stains of SDS-PAGE separated eluates from Flag immumoprecipitations of lysates from three mock (GFP) and three FlagDNAJB8 ${ }^{\mathrm{H} 31 \mathrm{Q}}$ transfected HEK293T cells. Cells were treated with crosslinker prior to lysis, and immunoprecipitates were washed with high stringency RIPA buffer prior to elution.

\section{Figure S3.}

A. Volcano plots for FlagDNAJB8 ${ }^{\mathrm{H} 31 \mathrm{Q}}$ immunoprecipitations with $\mathrm{p}$-values determined by ordinary (blue) and moderated (red) Student's t-tests. Direct comparison of p-values are plotted below, with the dotted line demonstrating unity.

B. Direct comparison of $p$-values for moderated Student's $t$ test and Pearson's correlation based $t$ test. The dotted line demonstrates unity.

C. Direct comparison of $\mathrm{q}_{\mathrm{BH}}$ values for moderated Student's $\mathrm{t}$ test and Pearson's correlation based $t$ test. The dotted line demonstrates unity.

Figure S4. Silver stained SDS-PAGE gel of eluates from one mock (GFP) sample and five samples dosed with increasing concentration of FlagDNAJB8 ${ }^{\mathrm{H} 31 \mathrm{Q}}$. Cells were treated with crosslinker prior to lysis, and immunoprecipitates were washed with high stringency RIPA buffer prior to elution.

\section{Figure S5.}

A. Representative silver stain of SDS-PAGE separated Flag immunoprecipitates from HEK293T

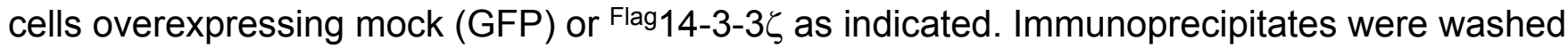
with gentle (low detergent) buffer. 


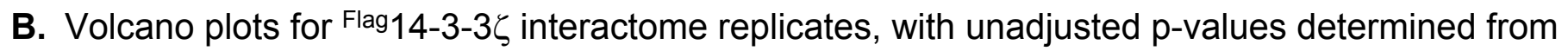
unpaired, two-way moderated Student's t and Pearson's correlation.

\section{Figure S6.}

A. Comparison of identified prey $\left(\mathrm{q}_{\mathrm{BH}}<0.01\right)$ between replicates for the two analysis methods.

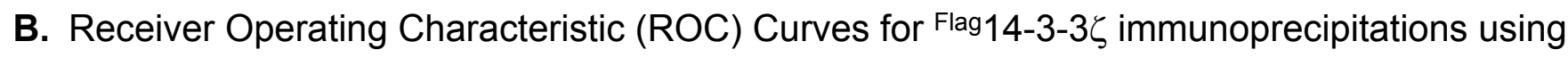
true interactors as determined from BioGRID ${ }^{1}$. True positive interactors were proteins that were found in at least three different AP-MS studies or at least two AP-IB studies. True negative interactors were total human cell lysate proteins identified as significant Dynabead contaminants reported in the CRAPome, excluding interactors from BioGRID². Replicate numbers for the two statistical approaches to analyzing the Bait vs. Mock experiments correspond to the same experiment.

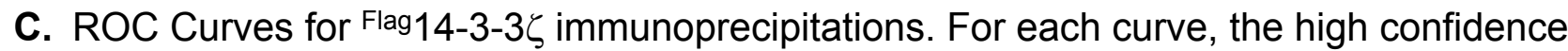
interactions (Bonferonni-adjusted $p$-value $<0.001$ over all replicate runs) were taken as the true interactors, while proteins with an unadjusted p-value above 0.7 were taken as false prey. Replicate numbers for the two statistical approaches to analyzing the Bait vs. Mock experiments correspond to the same experiment.

D. Bar graph illustrating Area Under the Curve for ROC Curves in Fig. S5C. Four replicates of each Bait vs. Mock and Dosed experiments are shown.

Figure S7: Q-Q plots comparing the cumulative distribution functions of experimental data against truncated normal distribution determined from the experimental mean and standard deviations. Plots that deviate sharply from unity, represented as a dashed line, indicate that the data is not welldescribed by a normal distribution. 
A. Plot inspecting the normality of Prey:Bait Mean Ratios in a bait-transfected sample. The deviation from normality is reflected by a depletion of values from the low end of a normal distribution. This could be because potential prey that has a low Prey:Bait ratio is less likely to be identified during data-dependent analysis. The data shown in this plot is drawn from FlagDNAJB8 ${ }^{\mathrm{H} 31 \mathrm{Q}}$ IP Replicate \#3.

B. Plot inspecting the normality of non-interactor intensities in untransfected samples; these represent non-specific bead association of non-interactors. There is little deviation from

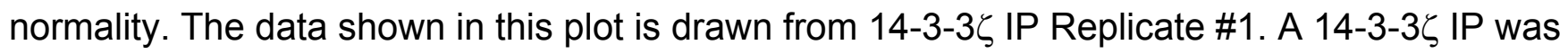
chosen because the gentle wash buffer used allows a higher number of non-interactors.

C. Plot inspecting the normality of interactor intensities in an untransfected sample; these represent non-specific bead association. These samples are for highly skewed from a normal distribution, with a high concentration of low values. The data shown in this plot is drawn from FlagDNAJB8 ${ }^{\mathrm{H} 31 \mathrm{Q}}$ IP Replicate \#3. 

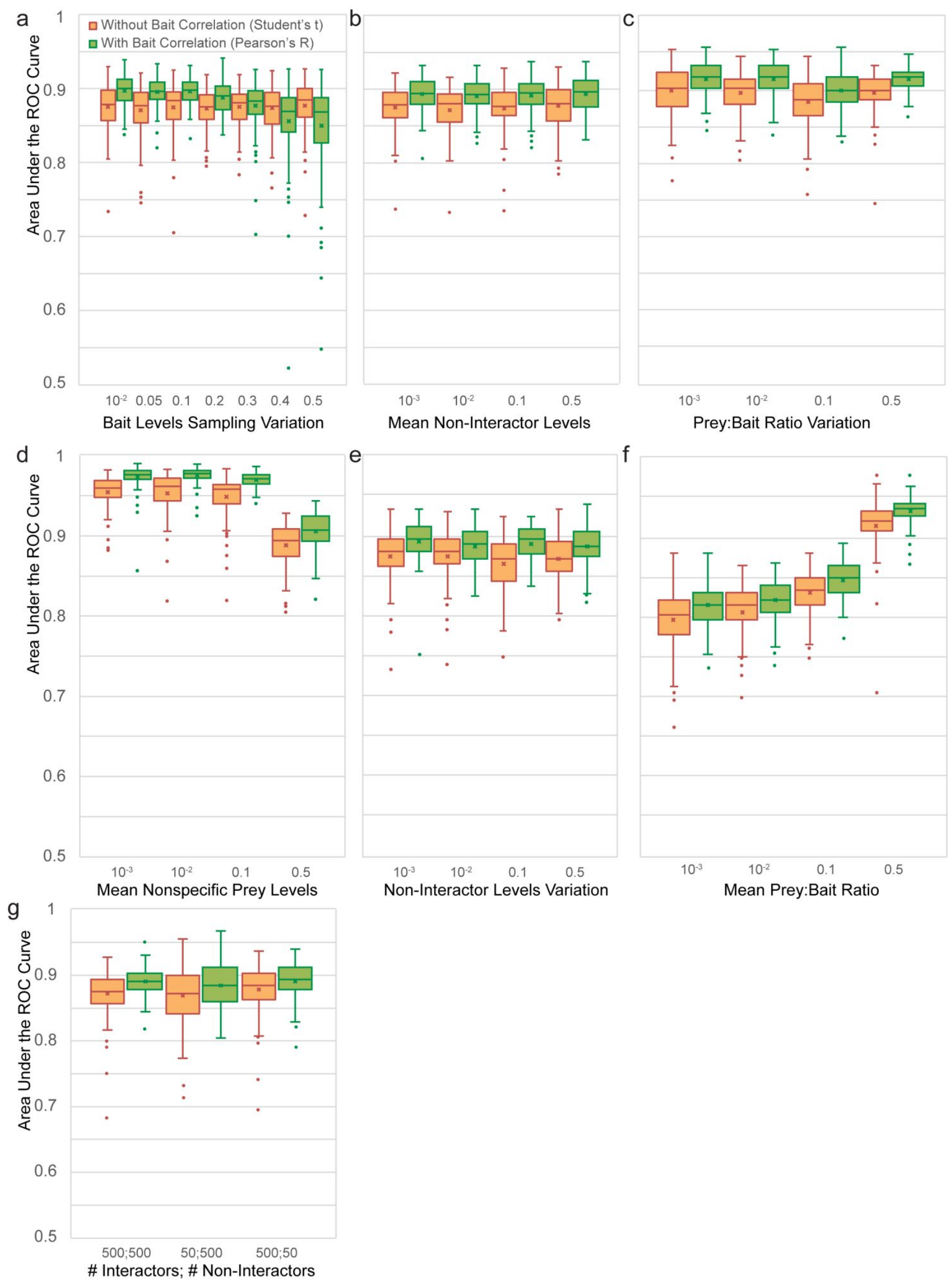

Figure S1 
20200128_MM_V_52_B8-8ug-lys-5m_4 \#1101 RT: 45.14 AV: 1 NL 5 F: FTMS + p NSI Full ms2 720.37@cid35.00 [185.00-2000.00]

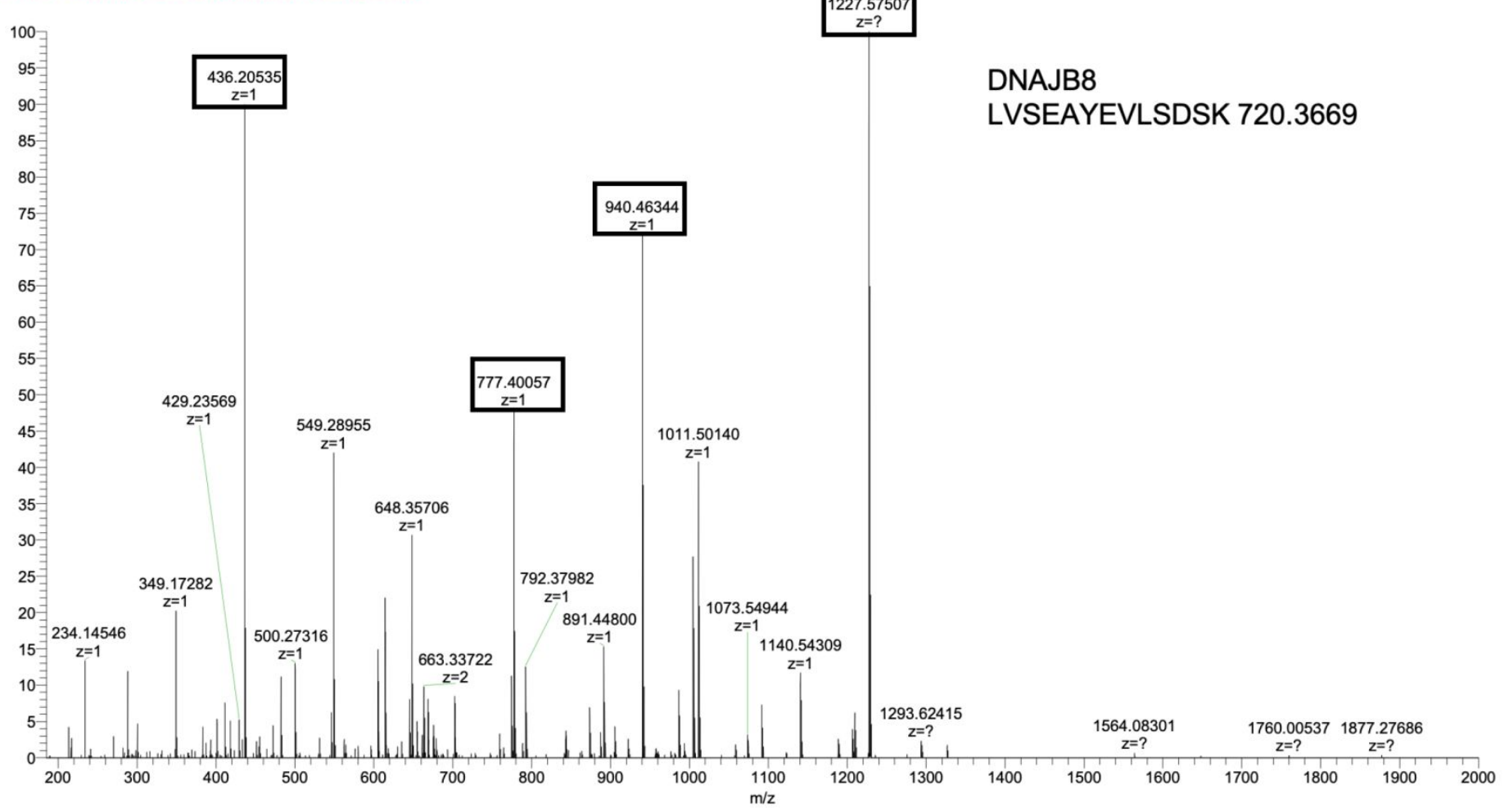

20200128_MM_V_52_B8-8ug-lys-5m_4 \#114 RT: 26.36 AV: 1 NL:

F: FTMS + p NSI Full ms2 710.83@cid35.00 [185.00-2000.00]

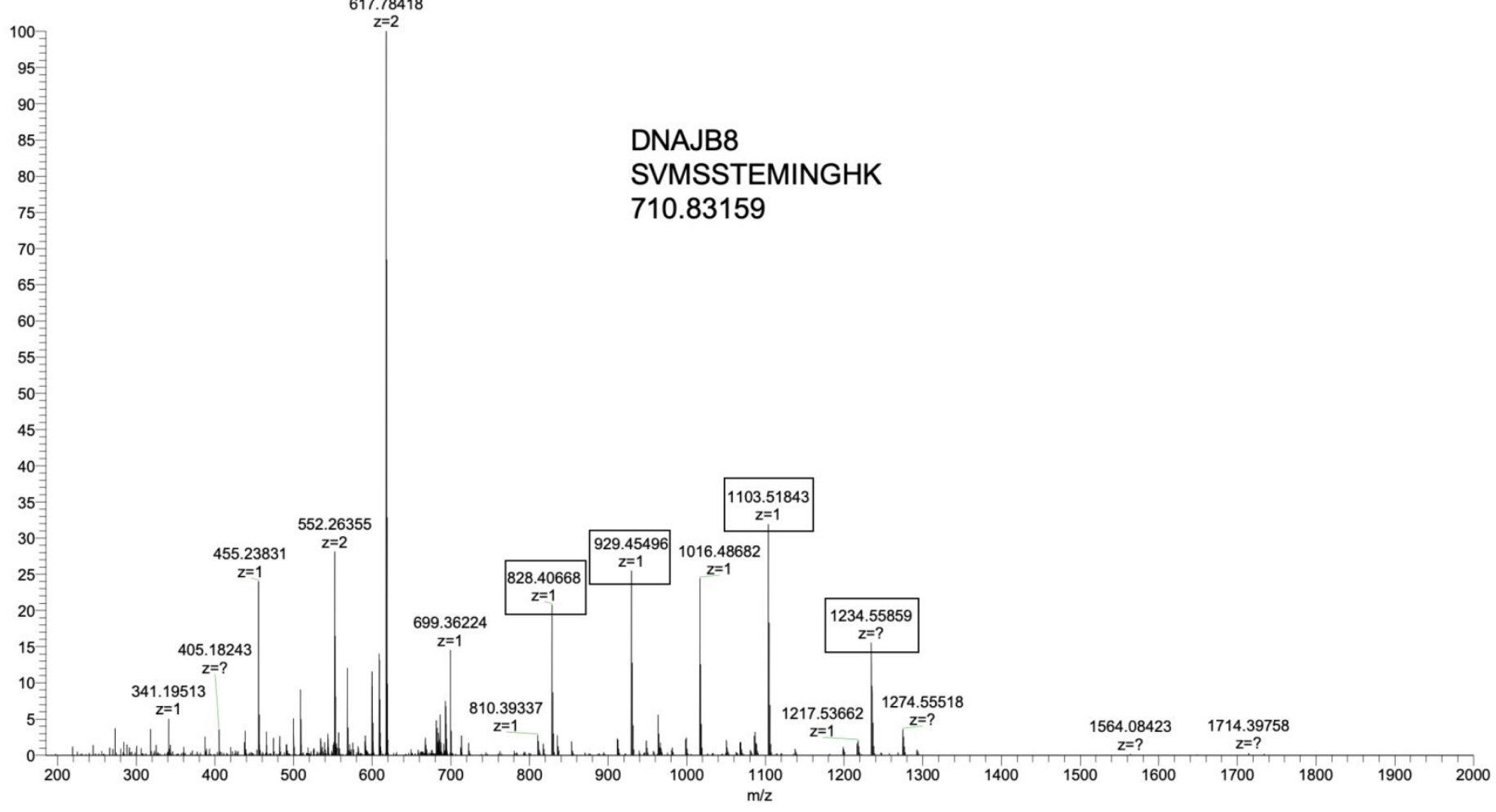


20200128_MM_V_52_B8-8ug-lys-5m_4 \#476 RT: 35.13 AV: 1 NL: F: FTMS + p NSI Full ms2 445.72@cid35.00 [110.00-2000.00]

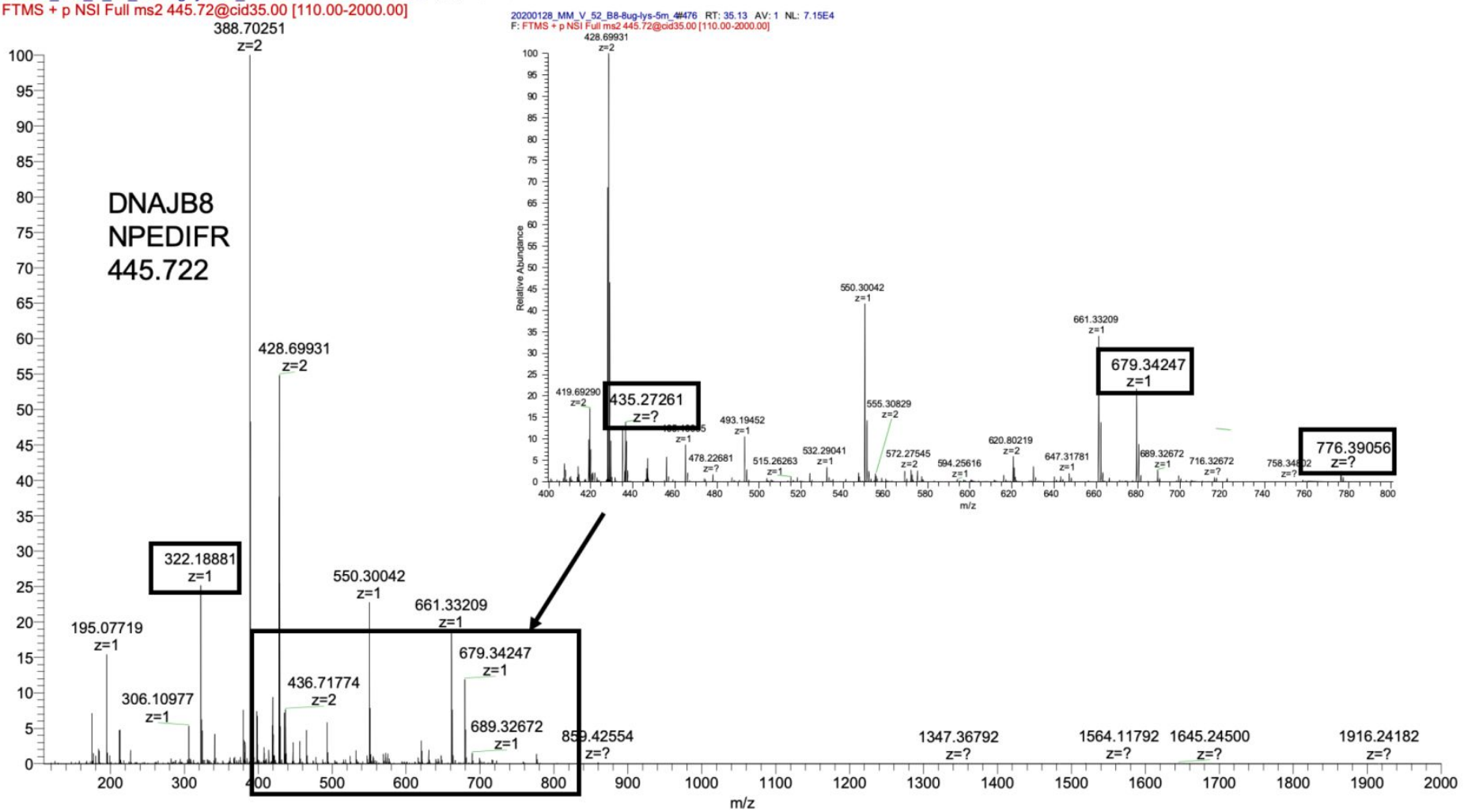

20200128_MM_V_52_B8-8ug-lys-5m_4 \#1134 RT: 45.61 AV: 1 NL. F: FTMS + p NSI Full ms2 696.99@cid35.00 [180.00-2000.00]

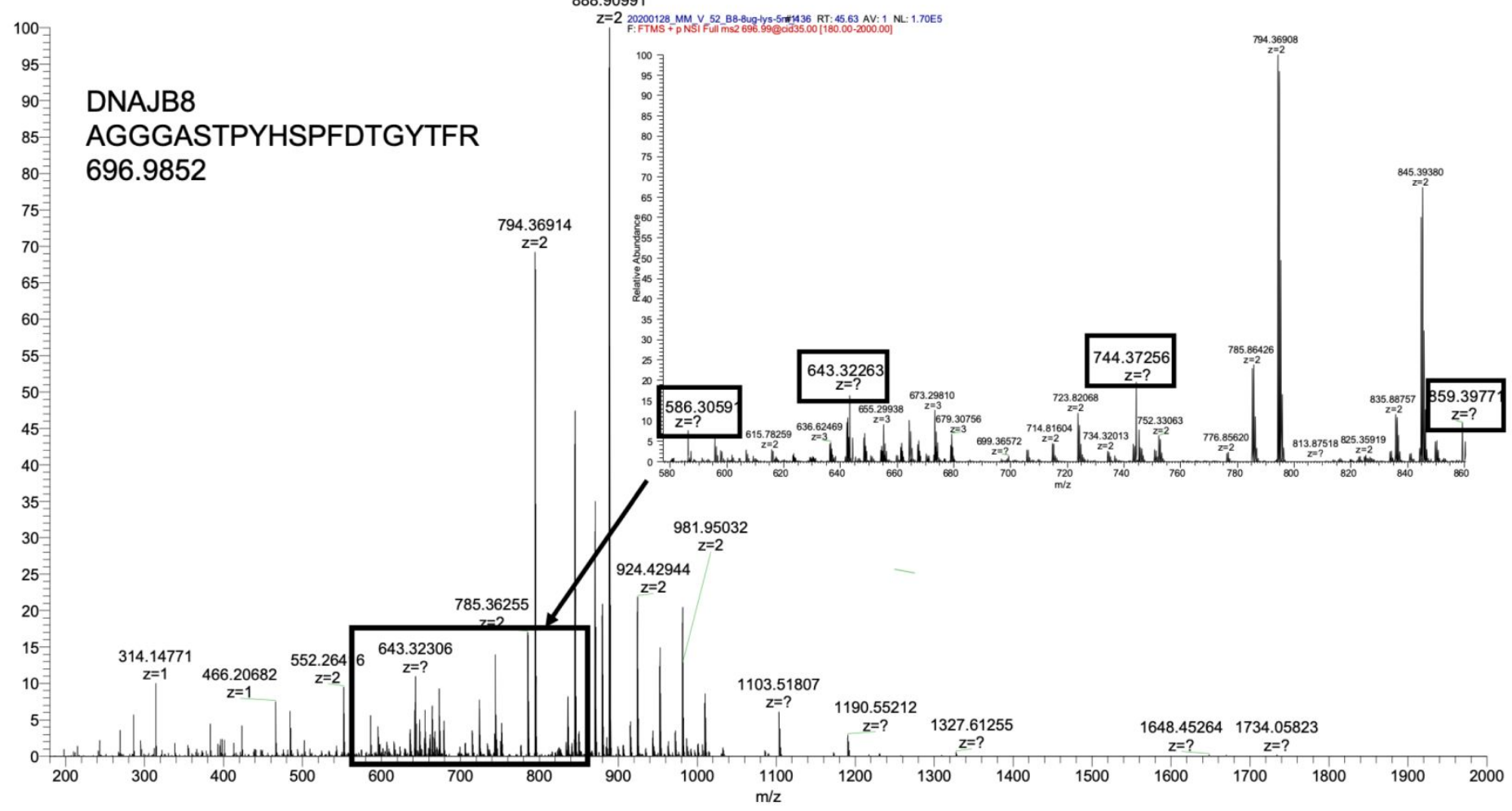


20200128_MM_V_52_B8-8ug-lys-5m_4 \#709 RT: 38.46 AV: 1 NL: F: FTMS + p NSI Full ms2 606.80@cid35.00 [155.00-2000.00]

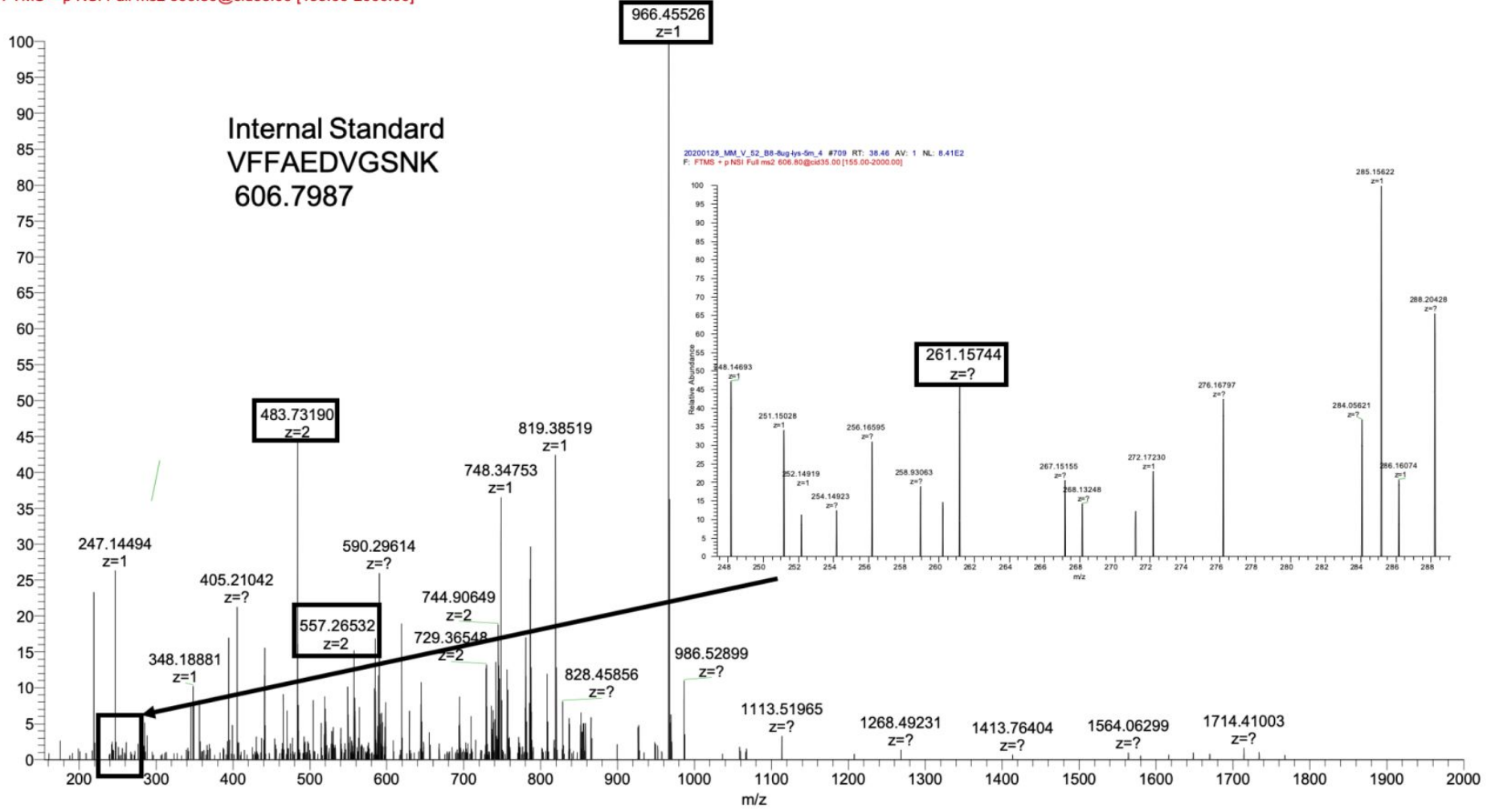

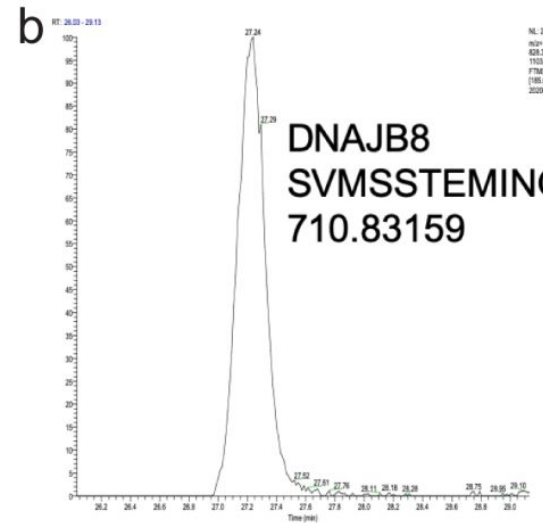

DNAJB8 AGGGASTPYHSPFDTGYTFR

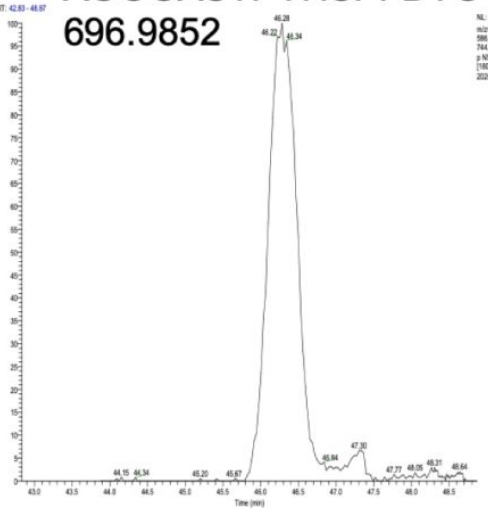

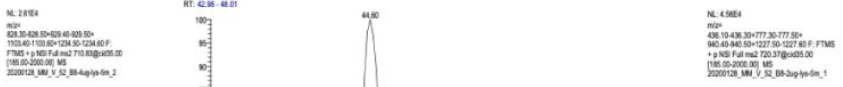

DNAJB8

LVSEAYEVLSDSK

720.3669

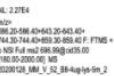

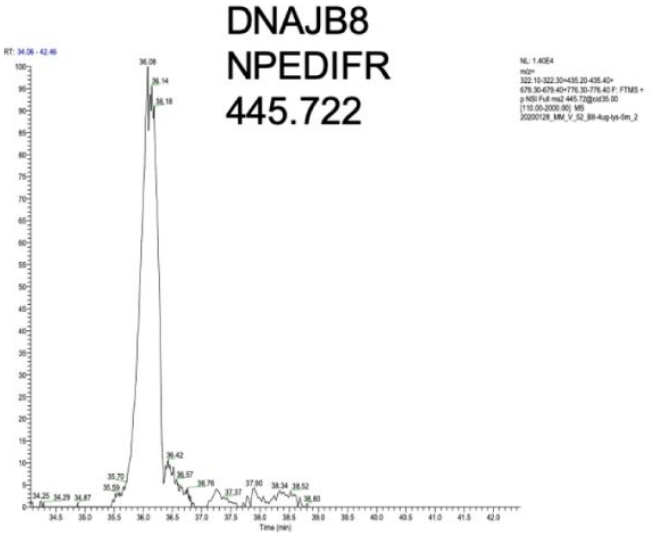

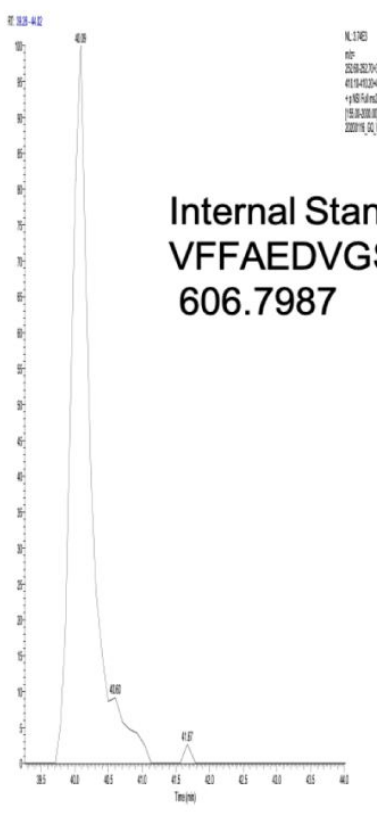


C

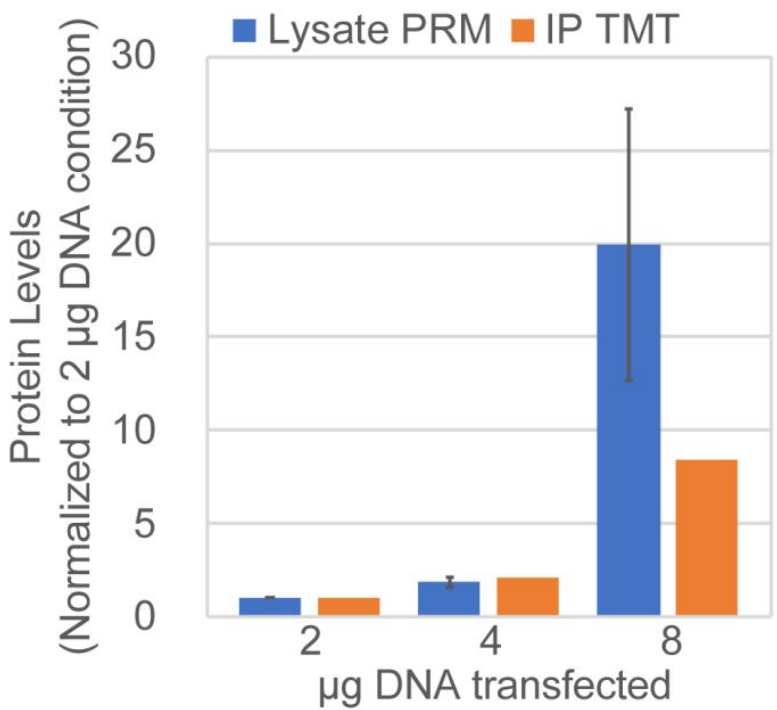

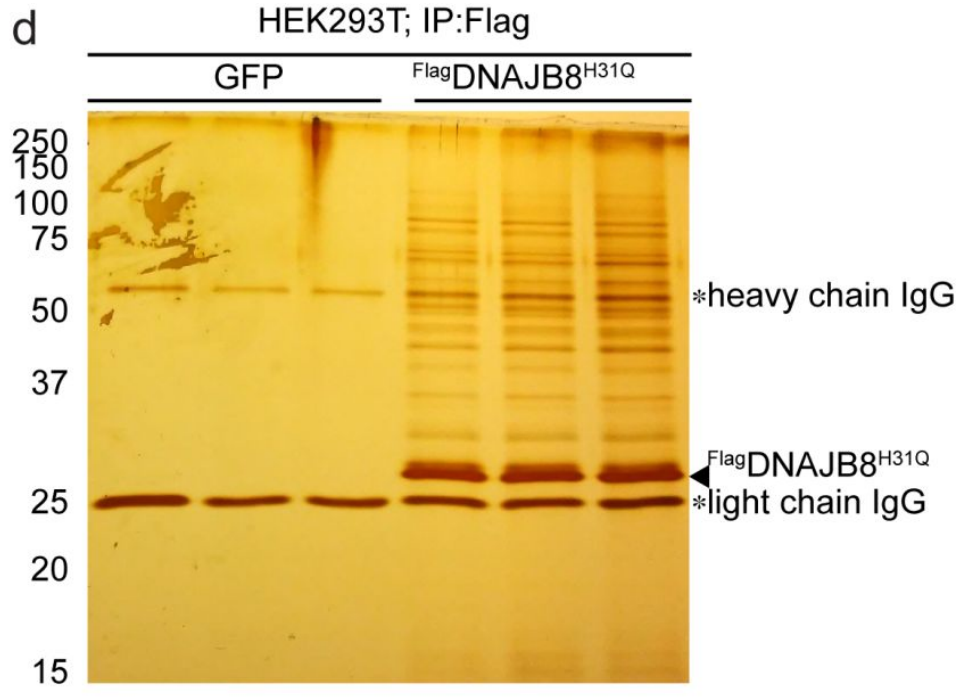

Figure S2 
a Comparison of moderated and ordinary $p$ values for DNAJB8 ${ }^{\mathrm{H} 1 \mathrm{Q}}$ TMT-AP-MS
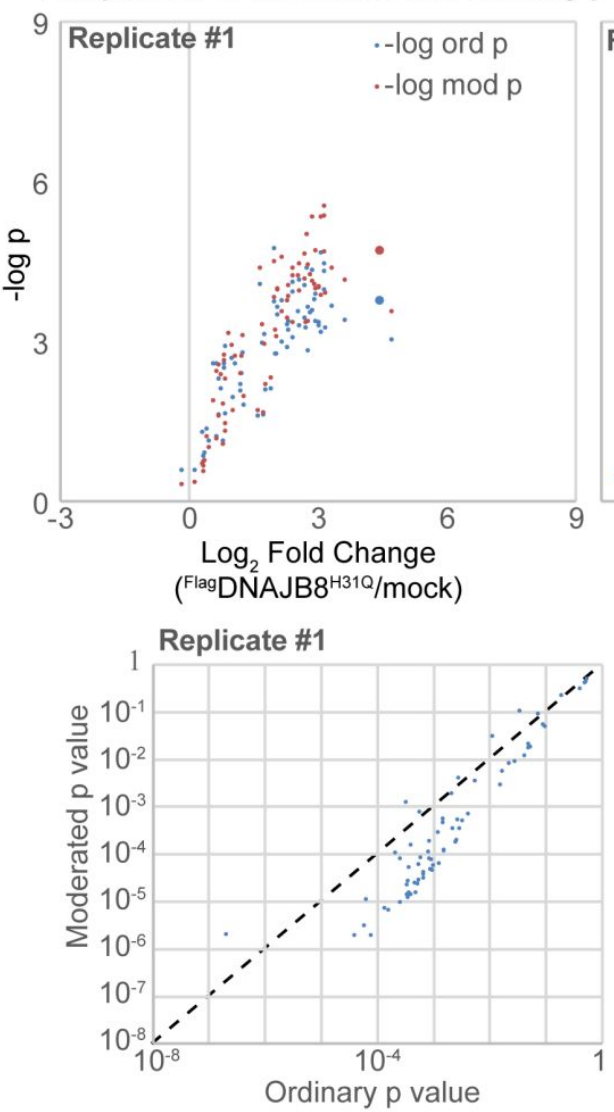

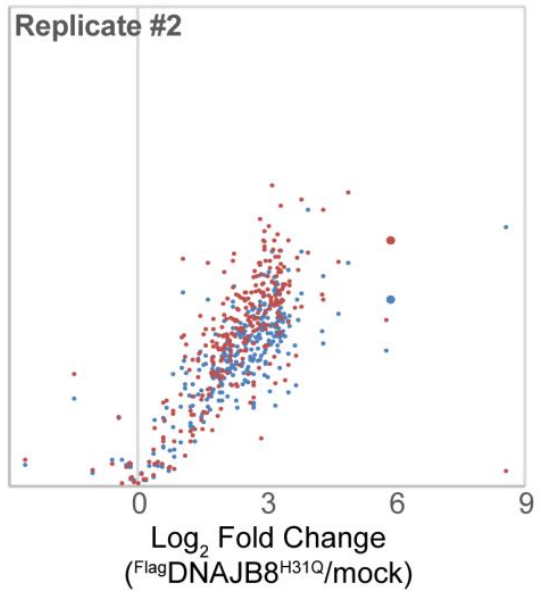

Replicate \#2

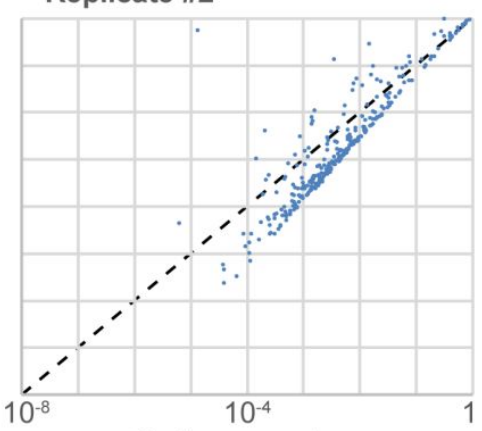

Ordinary $\mathrm{p}$ value

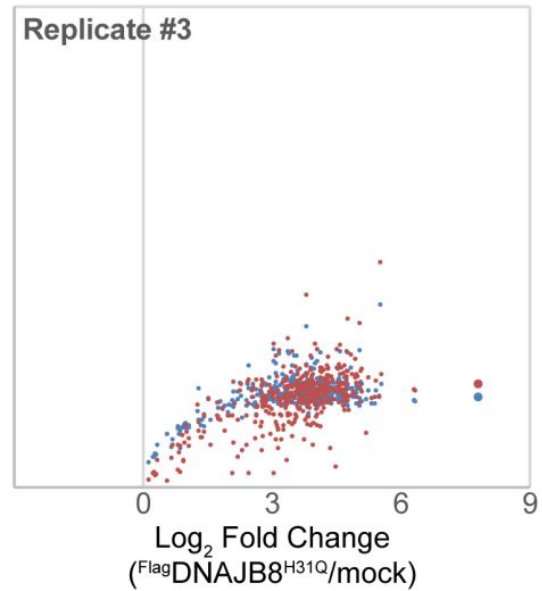

Replicate \#3

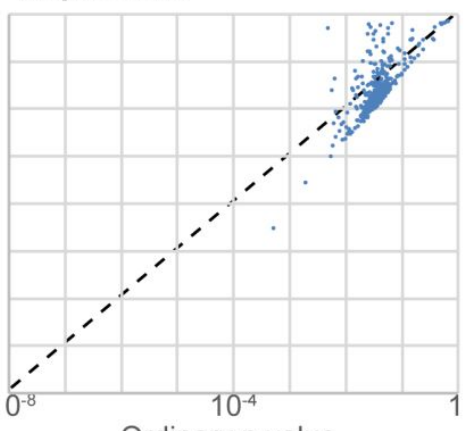

Ordinary $p$ value

b Comparison of moderated Student's $t$ test $p$ values and Pearson's $p$ values for DNAJB8 ${ }^{H 310}$ TMT-AP-MS
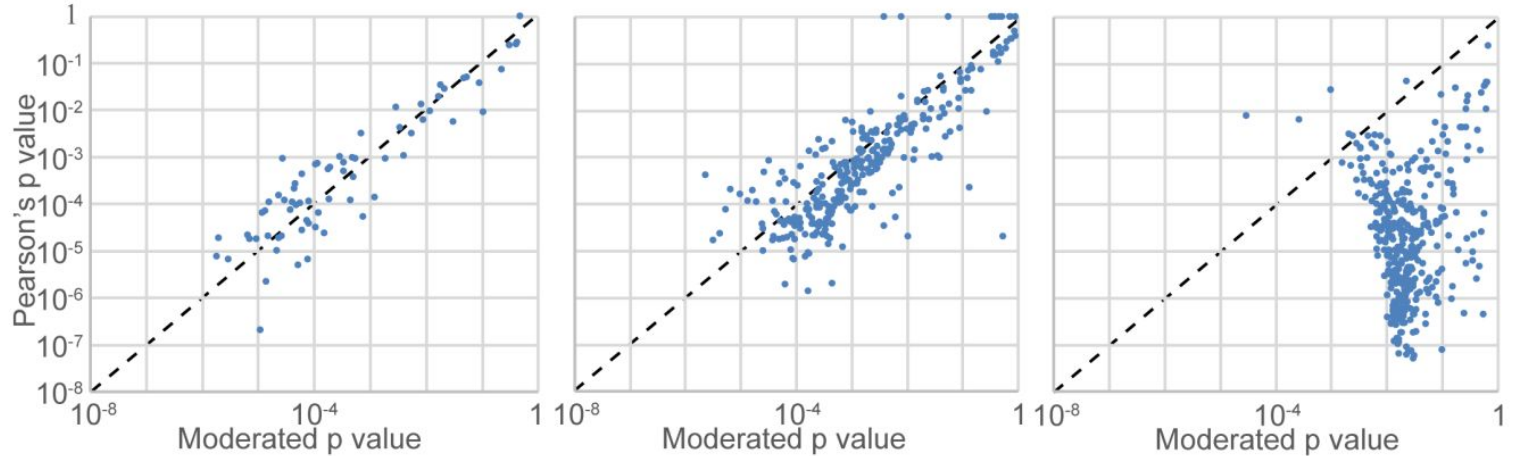

C Comparison of moderated Student's t test $\mathrm{q}_{\mathrm{BH}}$ values and Pearson's $\mathrm{q}_{\mathrm{BH}}$ values for DNAJB8 ${ }^{\mathrm{H} 31 \mathrm{Q}}$ TMT-AP-MS
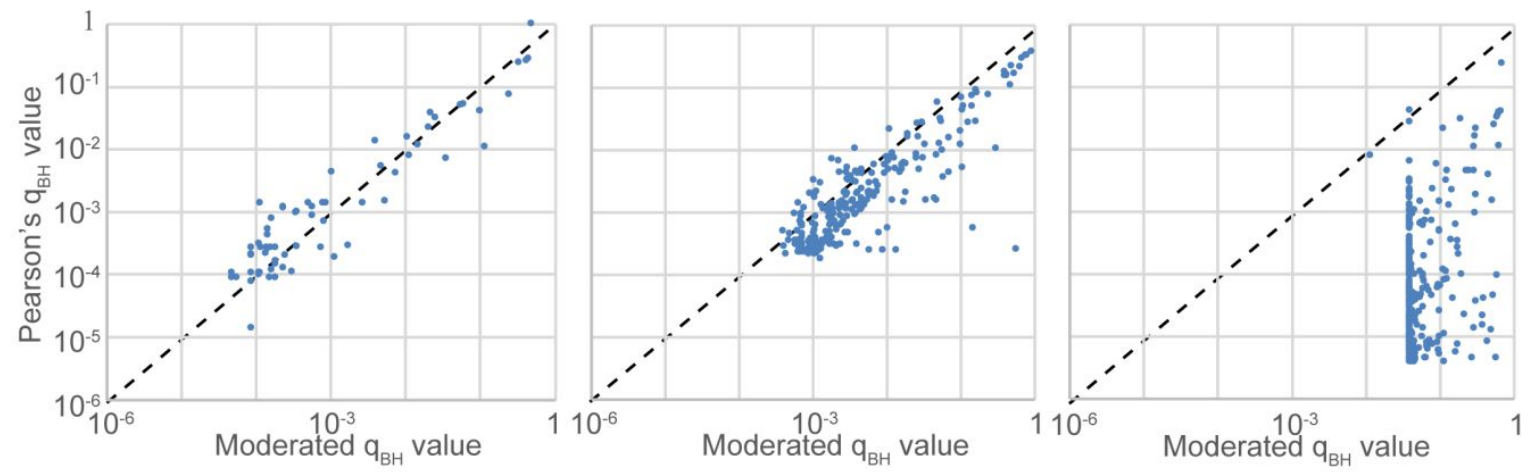

Figure S3 


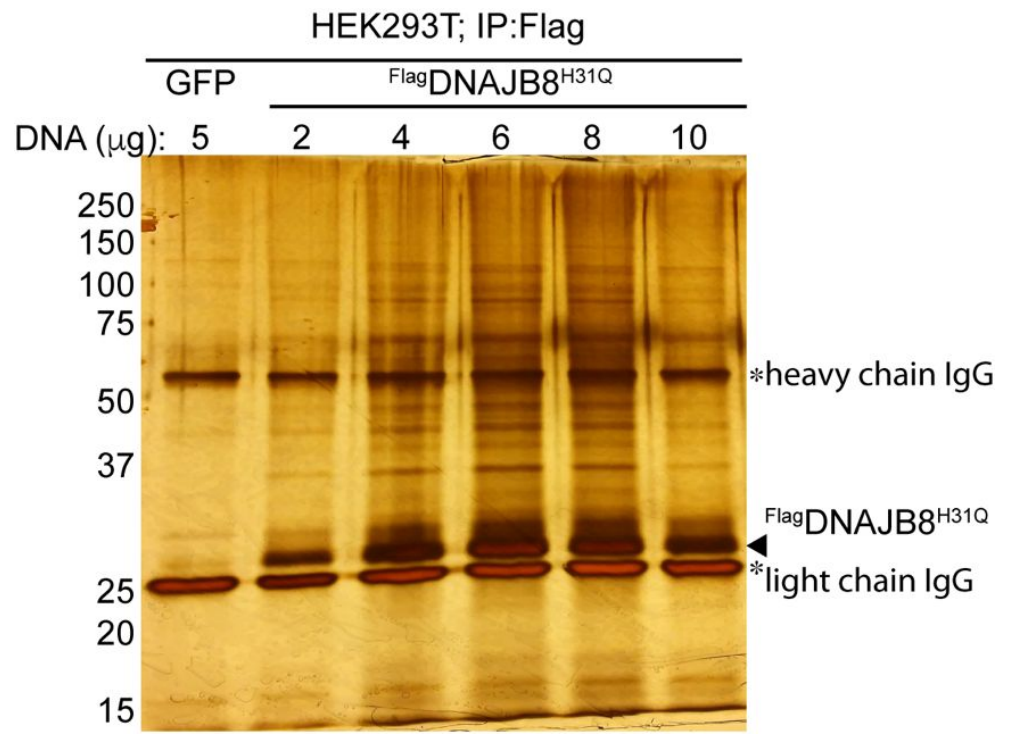

Figure S4 


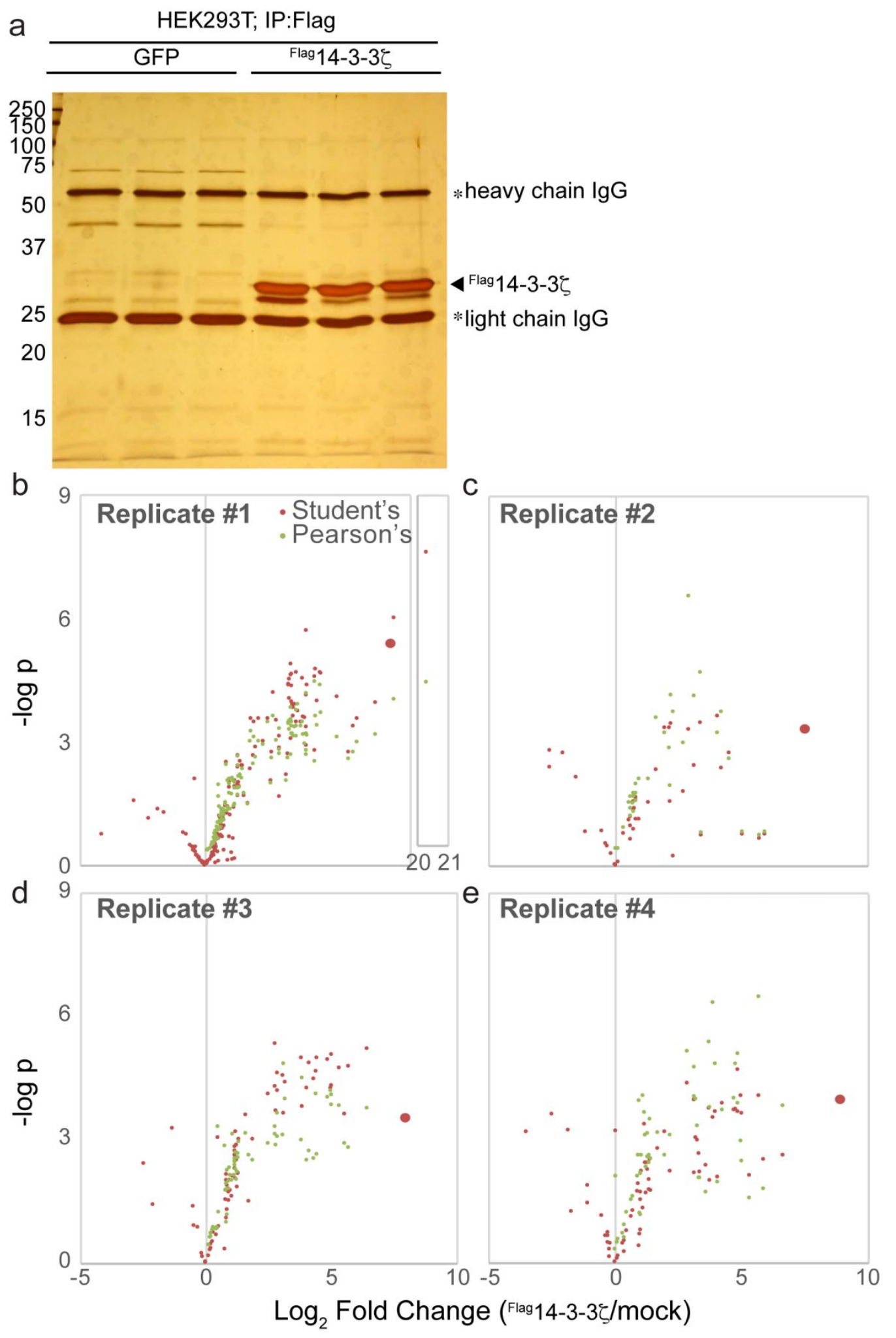

Figure S5 


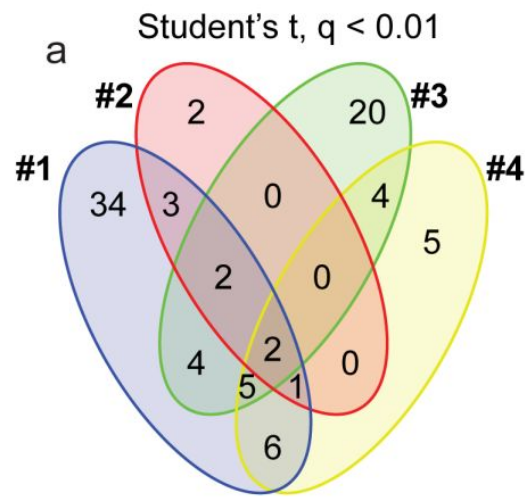

b Interactors from BioGRID vs. CRAPome

14-3-3弓 vs. Mock

Pearson's $r, q<0.01$
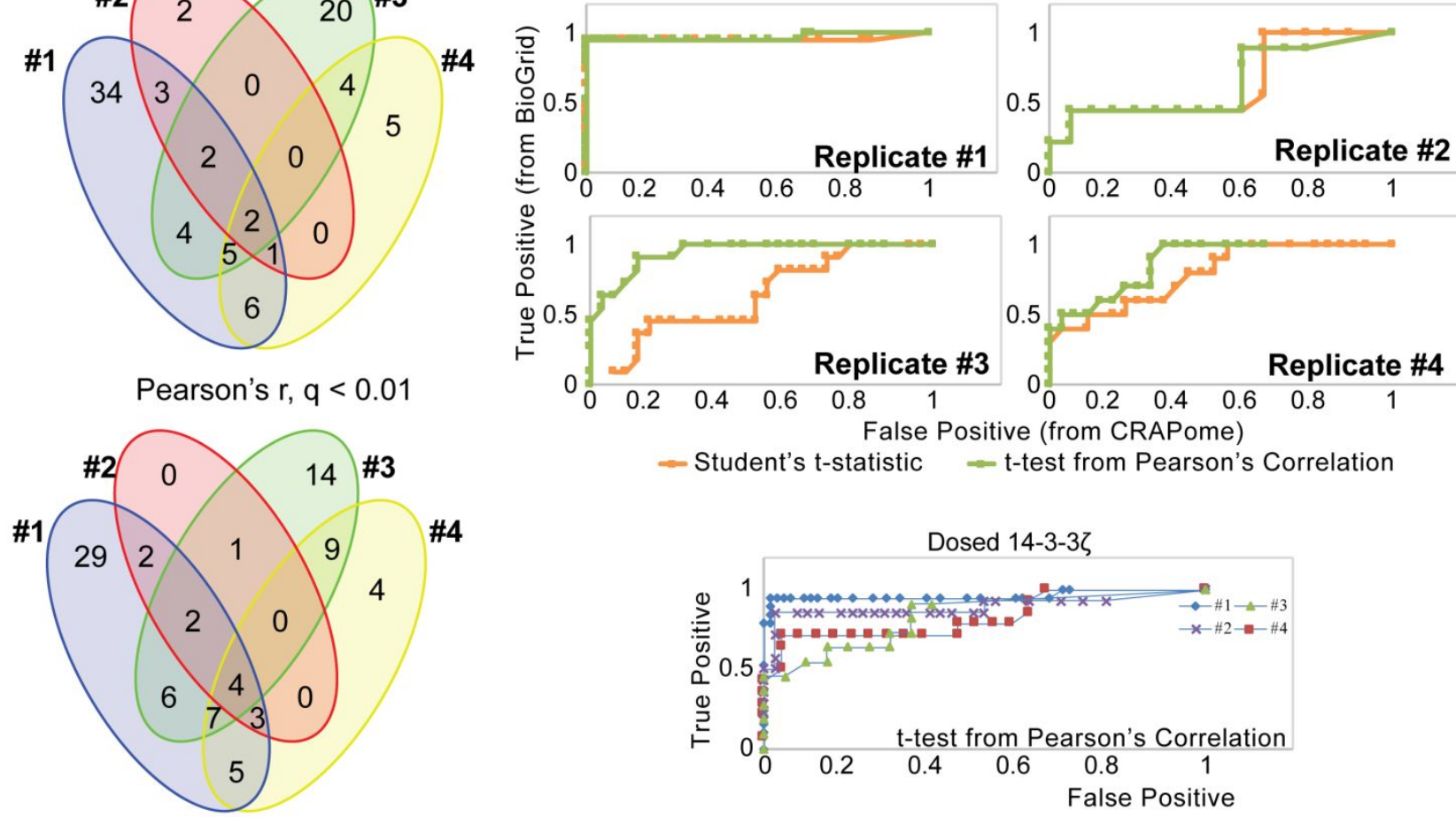

- Student's t-statistic - t-test from Pearson's Correlation

\#4
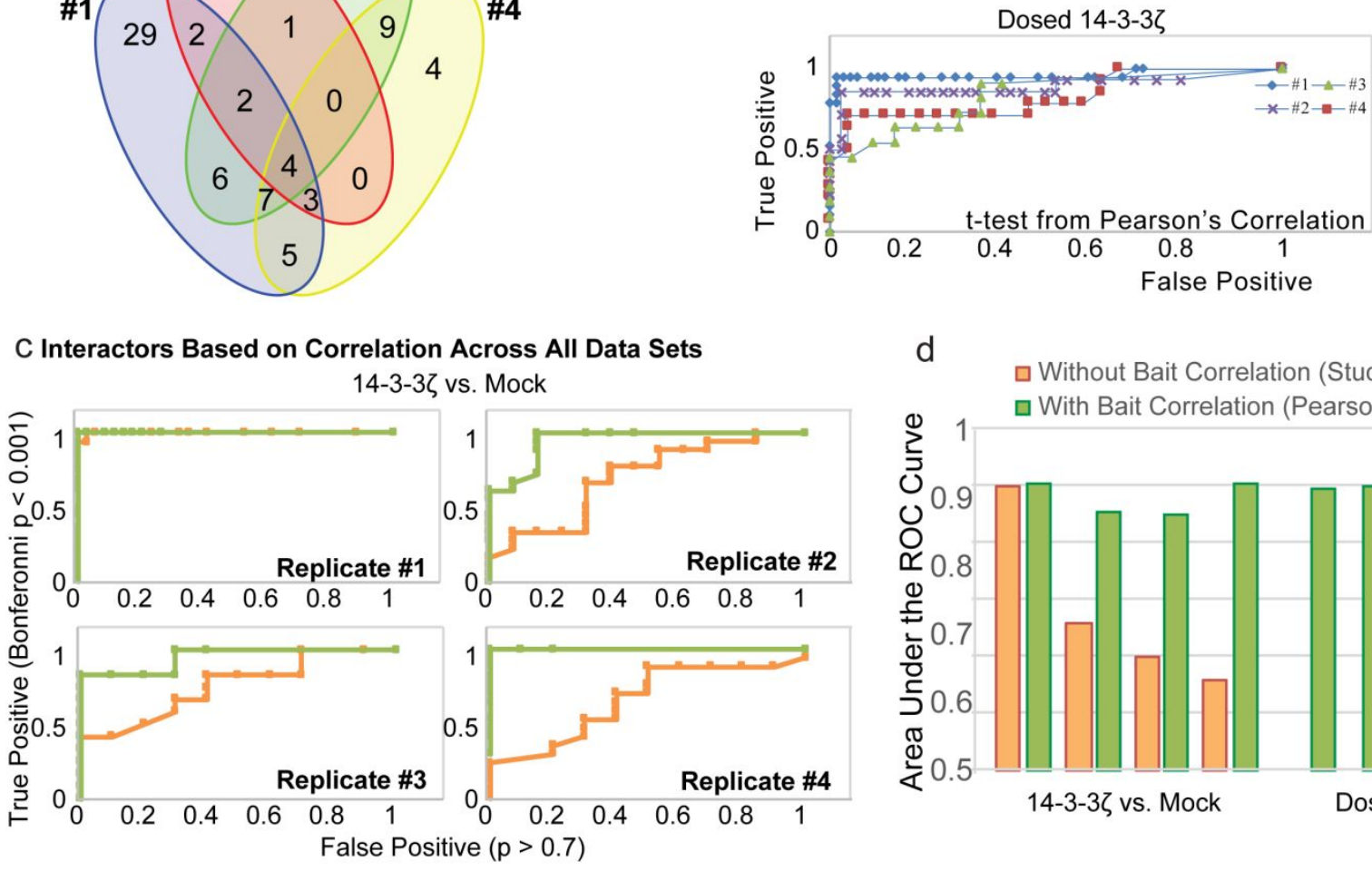

d

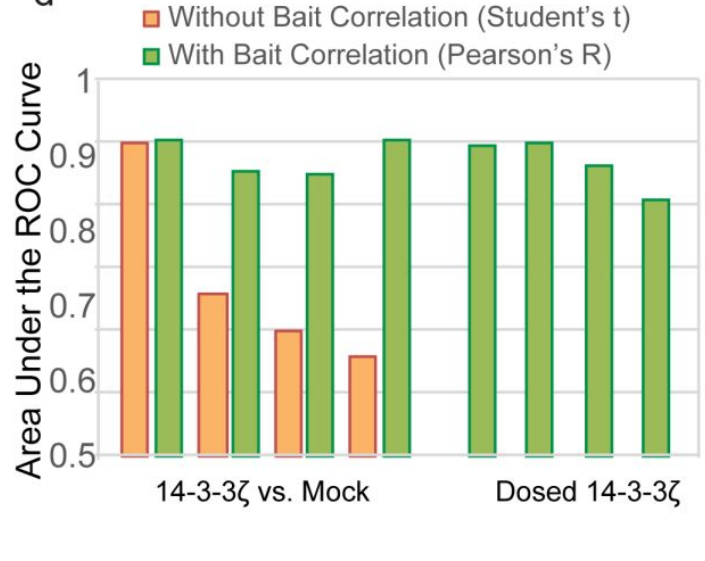

- Student's t-statistic - t-test from Pearson's Correlation

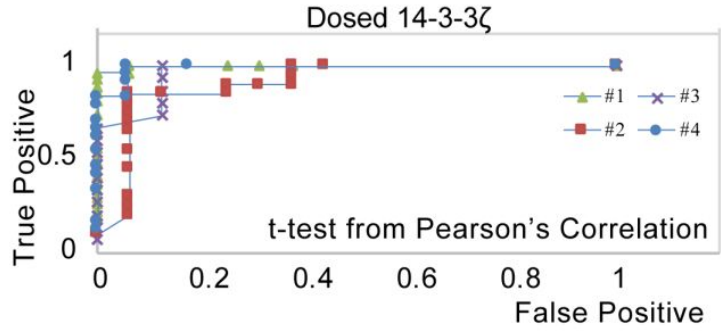

Figure S6 
a

Q-Q Plot Testing Normality of

Prey:Bait Ratios in Untransfected Samples

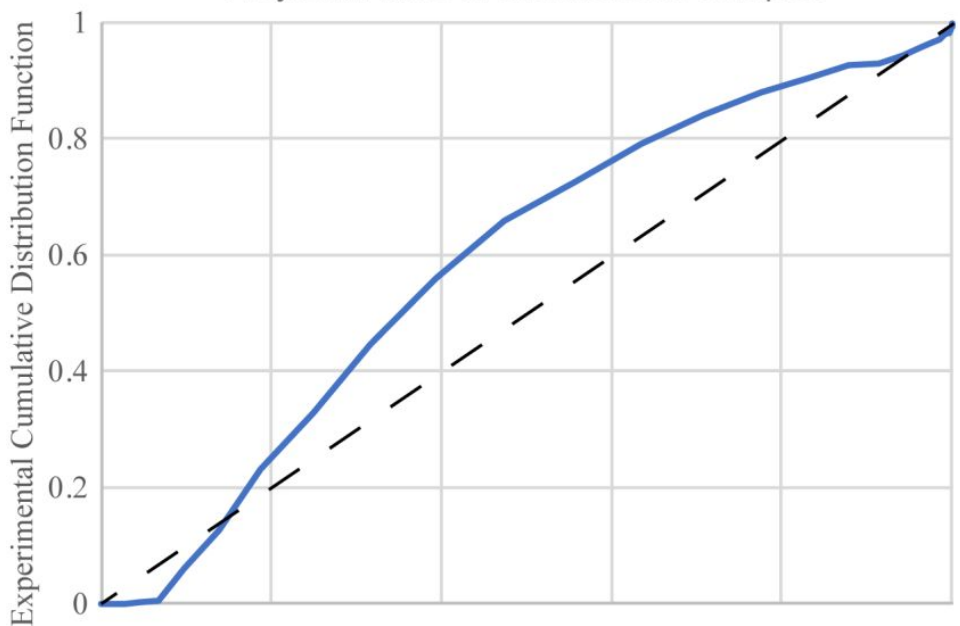

b Q-Q Plot Testing Normality of

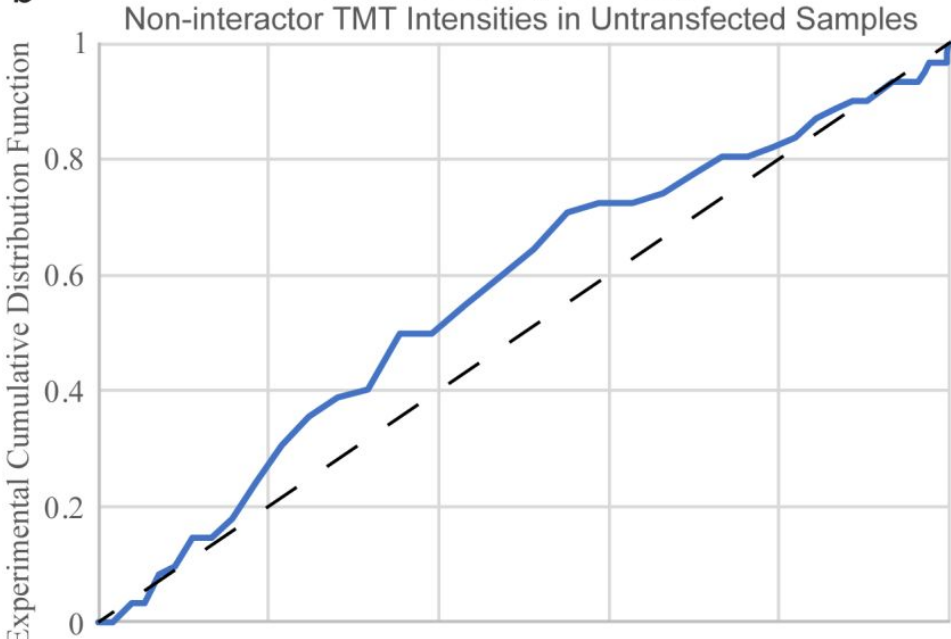

C Q-Q Plot Testing Normality of

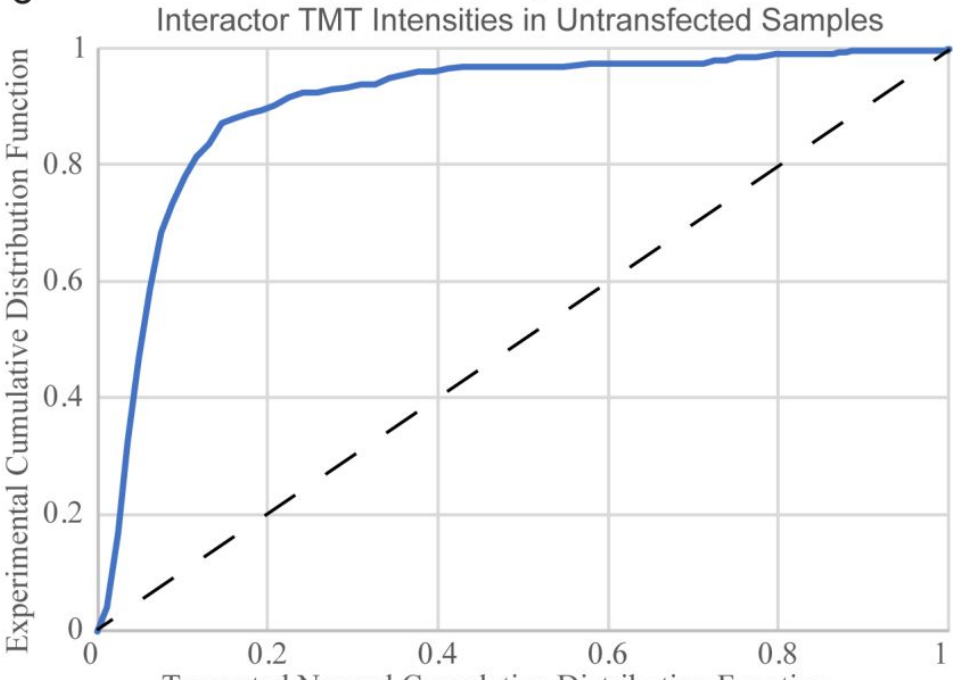

Truncated Normal Cumulative Distribution Function

Figure S7 


\section{SUPPLEMENTAL METHODS}

\section{Simulations}

Each parameter is pulled from a truncated normal distribution with mean and variance parameters as described in Supplemental Table 2. $\epsilon_{i j}$ represents sampling variation. Each protein is assumed to have a non-specific background intensity $\mu^{n s}$ independent of bait levels. Under this simple model, the levels of a non-interacting protein $i$ in the TMT channel $j$ is taken as:

$$
T M T_{i j}^{n i}=\mu_{i}^{n i, n s} \epsilon_{i j}^{n i, n s}
$$

where $\mu_{i}^{n i, n s}$ is the mean intensity of the $i$ non-interacting protein. The levels of the bait protein consist of a non-specific and specific term:

$$
T M T_{j}^{b a i t}=\mu^{b a i t, n s} \epsilon_{j}^{b a i t, n s}+\delta \mu_{j}^{b a i t} \epsilon_{j}^{b a i t}
$$

where $\delta=1$ in the three "bait" channels and $\delta=0$ in the three "mock" channels. Prey intensities also consist of a specific and non-specific term:

$$
T M T_{k j}^{p r e y}=\mu_{k}^{p r e y, n s} \epsilon_{k j}^{p r e y, n s}+\delta R_{k} \mu_{j}^{b a i t} \epsilon_{k j}^{p r e y}
$$

where $R_{k}$ represents the mean ratio of the $k$ protein to bait. For each simulation, 100 replicates were ran, with each replicate including three "bait" channels and three "mock" channels. The Mathematica code is included in this supplemental document.

\section{TMT-MuDPIT Analysis of Interactomes}

Only MS grade organic solvents were used during sample preparation. Buffer A is $0.1 \%$ formic acid, $5 \%$ acetonitrile in water. Buffer $B$ is $0.1 \%$ formic acid, $80 \%$ acetonitrile in water. Buffer $\mathrm{C}$ is $500 \mathrm{mM}$ 
ammonium acetate in Buffer A. Proteins in eluates were precipitated by methanol/chloroform precipitation and pellets air-dried, followed by resuspension in $1 \%$ Rapigest (Waters) in water. Resuspended protein solutions were then brought to $50 \mathrm{uL}$ in $100 \mathrm{mM}$ HEPES, pH 8.0, reduced with $10 \mathrm{mM}$ TCEP (Millipore Sigma) for $30 \mathrm{~min}$ at $37^{\circ} \mathrm{C}$, alkylated with $5 \mathrm{mM}$ iodoacetamide (Millipore Sigma) for $30 \mathrm{~min}$ in the dark and at ambient temperature, and digested overnight at $37^{\circ} \mathrm{C}$ with agitation (600 rpm) in the presence of $0.5 \mu \mathrm{g}$ sequencing grade trypsin (Thermo Fisher Scientific). TMT isotopic labels (Pierce) were resuspended (100 ug/80 $\mu \mathrm{L}$ acetonitrile) and $40 \mu \mathrm{L}$ of label was added to each $100 \mu \mathrm{L}$ sample of digested peptides. Several runs were searched for the presence of unlabeled peptides by allowing TMT labeling as a dynamic modification, and results indicated an unlabeled fraction similar to the false discovery rate. Samples were labeled for 1 hour at ambient temperature, followed by quenching with $0.4 \%$ ammonium bicarbonate at ambient temperature for 1 hour. Samples were pooled, acidified, centrifuged for $30 \mathrm{~min}$ at $21,100 \mathrm{xg}$ to remove any insoluble debris, and then dried by centrifugal evaporation to $10 \mu \mathrm{L}$. Solutions were then brought to $200 \mu \mathrm{L}$ in Buffer $\mathrm{A}$, incubated at $37^{\circ} \mathrm{C}$ for 1 hour, and centrifuged for $30 \mathrm{~min}$ at $21,100 \times \mathrm{g}$ to complete elimination of Rapigest. Samples were analyzed using two dimensional LC/MS/MS on an LTQ Orbitrap Velos hybrid mass spectrometer (Thermo) interfaced with an Easy-nLC 1000 (Thermo) according to standard MuDPIT protocols ${ }^{5}$. Triphasic loading columns were prepared by polymerizing a Kasil 1624 frit into a $250 \mu \mathrm{m}$ diameter fused silica capillary (Agilent) and then packing with $2.5 \mathrm{~cm}$ reversed-phase $5 \mu \mathrm{m}$ Aqua C18 resin (Phenomenex), $2.5 \mathrm{~cm} 5 \mu \mathrm{m}$ strong cation exchange resin (Partisphere, GE Healthcare) and again with $2.5 \mathrm{~cm}$ reversed-phase $5 \mu \mathrm{m}$ Aqua C18 resin. Analytical columns were prepared by pulling $100 \mu \mathrm{m}$ diameter fused silica columns (Agilent) with a P-2000 laser tip puller (Sutter Instrument Co., Novato, CA), followed by packing with at least $15 \mathrm{~cm}$ reversed-phase $3 \mu \mathrm{m}$ Aqua $\mathrm{C} 18$ resin (Phenomenex). Analysis was performed using a six-cycle chromatographic run, with progressively increasing ammonium acetate salt bumps injected prior to each cycle $(0 \% \mathrm{C}, 25 \% \mathrm{C}, 50 \% \mathrm{C}, 75 \% \mathrm{C}$, 
$100 \%$ C, $90 \%$ C $+10 \%$ B; balance of each buffer $A$ ), followed by acetonitrile gradient ( 5 min from $1 \% B$ to $7 \% \mathrm{~B}, 60 \mathrm{~min}$ to $55 \% \mathrm{~B}, 15 \mathrm{~min}$ to $100 \% \mathrm{~B}, 5 \mathrm{~min}$ at $100 \% \mathrm{~B}, 5 \mathrm{~min}$ to $1 \% \mathrm{~B} ; 300 \mathrm{~nL} / \mathrm{min}$ flow rate). Eluted peptides were ionized by electrospray ( $3.0 \mathrm{kV}$ ) and scanned from 110 to $2000 \mathrm{~m} / \mathrm{z}$ in the Orbitrap with resolution 30000 in data dependent acquisition mode. The top ten peaks with charge states of 2+, $3+$, or 4+ from each full scan were fragmented by HCD using a stepped collision energy of $36 \%, 42 \%$, and $48 \%$, a 100 ms activation time, and a resolution of 7500 . Dynamic exclusion parameters were 1 repeat count, $30 \mathrm{~ms}$ repeat duration, 500 exclusion list size, $120 \mathrm{~s}$ exclusion duration, and $2.00 \mathrm{Da}$ exclusion width. MS/MS spectra were extracted using RAW Xtractor (version 1.1.0.19, available at fields.scripps.edu) without deisotoping and searched using ProLuCID ${ }^{6,7}$ against a Uniprot human proteome database (05/05/2016 release) containing 20245 human sequences (longest entry for each protein) concatenated with reverse sequences for each entry as the decoy set, plus 200 select known contaminants (e.g albumen, porcine trypsin, etc.). ProLuCID searches allowed for static modification of cysteine residues (57.02146 Da, acetylation) N-termini, and lysine residues (229.1629 Da, TMTtagging), half tryptic peptidolysis specificity, and mass tolerance of $20 \mathrm{ppm}$ for precursor mass and 20 ppm for product ion masses. Spectra matches were assembled and filtered by DTASelect2 (version 2.0.27) ${ }^{8}$. The stringency of spectral matching was chosen such that $<1 \%$ of identified peptides were from the decoy database. Decoy proteins, contaminants, and keratins were filtered from the final protein list. Quantitation in Census ${ }^{9}$ was performed by averaging TMT reporter ion intensities for all spectra associated with an individual peptide and deconvolution of isotopic impurity as reported in the lot analysis supplied by Thermo Fisher. Only unique peptides were used for quantification. Empty TMT channels were substituted with a "1", which is well below the threshold value for TMT quantification.

\section{Parallel Reaction Monitoring}

Lysates were desalted by chloroform/methanol precipitation. Protein pellets were solubilized in $8 \mathrm{M}$ urea in $50 \mathrm{mM}$ Tris $\mathrm{pH}$ 8, reduced with $10 \mathrm{mM}$ TCEP in $50 \mathrm{mM}$ Tris $\mathrm{pH} 8$ for $30 \mathrm{~min}$. at ambient 
temperature, alkylated with $5 \mathrm{mM}$ iodoacetamide for $30 \mathrm{~min}$. in the dark at ambient temperature, and diluted 3-fold in $50 \mathrm{mM}$ Tris $\mathrm{pH} 8$ to lower the urea concentration to $2 \mathrm{M}$. Trypsin digestion was performed with $100: 1$ sequencing grade trypsin $20 \mathrm{~h}$ at $37^{\circ} \mathrm{C}, 600 \mathrm{rpm}$. Peptides were scanned over scheduled $5 \mathrm{~min}$. windows centered around their average retention time, and isolated with a $2.0 \mathrm{~m} / \mathrm{z}$ isolation window. Peptides were fragmented with CID with a normalized collision energy of 35 , activation Q of 0.25 and activation time of $10 \mathrm{~ms}$. MS2 were acquired in the Orbitrap at 7500 resolution and saved in profile mode. Peptide separations by LC-MS proceeded between Buffer A $(5 \%$ acetonitrile: $95 \%$ water: $0.1 \%$ formic acid) and Buffer B ( $80 \%$ acetonitrile: $20 \%$ water: $0.1 \%$ formic acid) over a 100 minute gradient with the following segments: 1-5 minutes: 1-6\% Buffer B. 5-75 minutes: 636\% Buffer B. 75-80 minutes: 36-100\% Buffer B. 80-85 minutes: 100\% Buffer B. 85-90 minutes: 1001\% Buffer B. $90-100$ minutes: 1\% Buffer B. 
Table S1. Primers used for Molecular Cloning.

\begin{tabular}{|l|l|l|}
\hline Primer Name & & Sequence \\
\hline DNAJB8 PIPES Vector & Fwd & 5'-GAC AGC AAG TAG GCG AAT TCA TCG ATA GAT CTG-3' \\
\hline DNAJB8 PIPES Vector & Rev & 5'-CTT CGT AGT AGT TAG CCA TAA GCT TGT CGT CAT CGT C-3' \\
\hline DNAJB8 PIPES Insert & Fwd & 5'-GAC GAT GAC GAC AAG CTT ATG GCT AAC TAC TAC GAA G-3' \\
\hline DNAJB8 PIPES Insert & Rev & 5'-CAG ATC TAT CGA TGA ATT CGC CTA CTT GCT GTC-3' \\
\hline DNAJB8 H31Q SDM & Fwd & 5'- CTT CGT TGG CAG CCC GAC AAG AAC CCT GAC AAT AAG-3' \\
\hline DNAJB8 H31Q SDM & Rev & 5'- GTT CTT GTC GGG CTG CCA ACG AAG GGC-3' \\
\hline 14-3-3z PIPES Vector & Fwd & 5'-GGA GAA GGA GGG GAA AAT TAA GCG AAT TCA TCG ATA GAT CTG-3' \\
\hline 14-3-3z PIPES Vector & Rev & 5'-GAA CCA GCT CAT TTT TAT CCA TAA GCT TGT CGT CAT CGT C-3' \\
\hline 14-3-3z PIPES Insert & Fwd & 5'-GAC GAT GAC GAC AAG CTT ATG GAT AAA AAT GAG CTG GTT C-3' \\
\hline 14-3-3z PIPES Insert & Rev & 5'-CAG ATC TAT CGA TGA ATT CGC TTA ATT TTC CCC TCC TTC TCC-3' \\
\hline
\end{tabular}


Table S2. Transitions for PRM Analysis of FlagDNAJB8 ${ }^{H 31 Q}$

\begin{tabular}{|l|c|l|l|}
\hline Sequence & Charge State & Precursor m/z & Retention Time (min.) \\
\hline SVMSSTEMINGHK & $2+$ & 710.8316 & 35.04 \\
\hline NPEDIFR & $2+$ & 445.722 & 44.95 \\
\hline LVSEAYEVLSDSK & $2+$ & 720.3669 & 26.19 \\
\hline AGGGASTPYHSPFDTGYTFR & $2+$ & 696.9852 & 38.19 \\
\hline
\end{tabular}


Table S3. Parameters for simulations of TMT-AP-MS Data

\begin{tabular}{|c|c|c|c|}
\hline Parameter & Symbol & Mean (Value in Fig. 1) & Variance (Value in Fig. 1) \\
\hline $\begin{array}{l}\text { Non-specific Non-interactor } \\
\text { Levels }\end{array}$ & $\mu_{i}^{n i, b g}$ & $\begin{array}{l}\text { NonSpecificNoninteractMean } \\
(0.3)\end{array}$ & $\begin{array}{l}\text { NonSpecificNoninteractStandard } \\
\text { Deviation (0.6) }\end{array}$ \\
\hline $\begin{array}{l}\text { Non-specific Non-interactor } \\
\text { Levels Sampling Variation }\end{array}$ & $\epsilon_{i j}^{n i, b g}$ & 1 & $\begin{array}{l}\text { NonSpecificNoninteract Channel } \\
\text { Standard Deviation }(0.2)\end{array}$ \\
\hline Non-specific Prey Levels & $\mu_{k}^{\text {prey,bg }}$ & NonSpecificPreyMean (0.1) & $\begin{array}{l}\text { NonSpecificPrey Standard } \\
\text { Deviation }(0.6)\end{array}$ \\
\hline $\begin{array}{l}\text { Non-specific Prey Levels } \\
\text { Sampling Variation }\end{array}$ & $\epsilon_{k j}^{p r e y, b g}$ & 1 & $\begin{array}{l}\text { NonSpecificPrey Channel } \\
\text { Standard Deviation (0.2) }\end{array}$ \\
\hline Prey:Bait Ratio & $R_{k}$ & RatioMean $(0.3)$ & Ratio Standard Deviation (0.3) \\
\hline $\begin{array}{l}\text { Prey:Bait Ratio Sampling } \\
\text { Variation }\end{array}$ & $\epsilon_{k j}^{p r e y}$ & 1 & $\begin{array}{l}\text { Ratio Channel Standard Deviation } \\
(0.2)\end{array}$ \\
\hline Non-specific Bait Levels & $\mu^{b a i t, b g}$ & NonSpecificBaitMean (0.1) & $\begin{array}{l}\text { NonSpecificBaitStandard } \\
\text { Deviation (0.01) }\end{array}$ \\
\hline $\begin{array}{l}\text { Non-specific Bait Levels } \\
\text { Sampling Variation }\end{array}$ & $\epsilon_{j}^{b a i t, b g}$ & 1 & $\begin{array}{l}\text { NonSpecificBait Channel } \\
\text { Standard Deviation (0.2) }\end{array}$ \\
\hline Bait Levels & $\mu_{j}^{\text {bait }}$ & 1 & $\begin{array}{l}\text { BaitLevelsStandardDeviation } \\
\text { (indicated) }\end{array}$ \\
\hline Bait Levels Sampling Variation & $\epsilon_{j}^{b a i t}$ & 1 & $\begin{array}{l}\text { BaitLevels Channel Standard } \\
\text { Deviation (0.2) }\end{array}$ \\
\hline
\end{tabular}


Table S6. Parameters for simulations determined from experimental data.

\begin{tabular}{|c|c|c|c|}
\hline Parameter & Symbol & Mean (Value in Fig. 6C) & Variance (Value in Fig. $6 \mathrm{C}$ ) \\
\hline $\begin{array}{l}\text { Non-specific Non-interactor } \\
\text { Levels }\end{array}$ & $\mu_{i}^{n i n s}$ & $\begin{array}{l}\text { NonSpecificNoninteractMean } \\
(0.02)\end{array}$ & $\begin{array}{l}\text { NonSpecificNoninteractStandard } \\
\text { Deviation }(0.02)\end{array}$ \\
\hline $\begin{array}{l}\text { Non-specific Non-interactor } \\
\text { Llevels Sampling Variation }\end{array}$ & $\epsilon_{i j}^{n i, n s}$ & 1 & $\begin{array}{l}\text { NonSpecificNoninteractChannel } \\
\text { StandardDeviation }(0.1)\end{array}$ \\
\hline Non-specific Prey Levels & $\mu_{k}^{\text {prey,ns }}$ & NonSpecificPreyMean (0.05) & $\begin{array}{l}\text { NonSpecificPreyStandard } \\
\text { Deviation (0.05) }\end{array}$ \\
\hline $\begin{array}{l}\text { Non-specific Prey Levels } \\
\text { Sampling Variation }\end{array}$ & $\epsilon_{k j}^{p r e y, n s}$ & 1 & $\begin{array}{l}\text { NonSpecificPreyChannelStandard } \\
\text { Deviation }(0.1)\end{array}$ \\
\hline Prey:Bait Ratio & $R_{k}$ & RatioMean (0.2) & RatioStandardDeviation (0.2) \\
\hline $\begin{array}{l}\text { Prey:Bait Ratio Sampling } \\
\text { Variation }\end{array}$ & $\epsilon_{k j}^{p r e y}$ & 1 & $\begin{array}{l}\text { RatioChannelStandardDeviation } \\
(0.1)\end{array}$ \\
\hline Non-specific Bait Levels & $\mu^{\text {bait }, n s}$ & NonSpecificBaitMean (0.01) & $\begin{array}{l}\text { NonSpecificBaitStandard } \\
\text { Deviation }(0.008)\end{array}$ \\
\hline $\begin{array}{l}\text { Non-specific Bait Levels } \\
\text { Sampling Variation }\end{array}$ & $\epsilon_{j}^{\text {bait,ns }}$ & 1 & $\begin{array}{l}\text { NonSpecificBaitChannelStandard } \\
\text { Deviation }(0.008)\end{array}$ \\
\hline Bait Levels & $\mu_{j}^{\text {bait }}$ & 1 & $\begin{array}{l}\text { BaitLevelsStandardDeviation } \\
\text { (indicated) }\end{array}$ \\
\hline Bait Levels Sampling Variation & $\epsilon_{j}^{\text {bait }}$ & 1 & $\begin{array}{l}\text { BaitLevelsChannelStandard } \\
\text { Deviation }(0.1)\end{array}$ \\
\hline
\end{tabular}


Mathematica Code for Simulations:

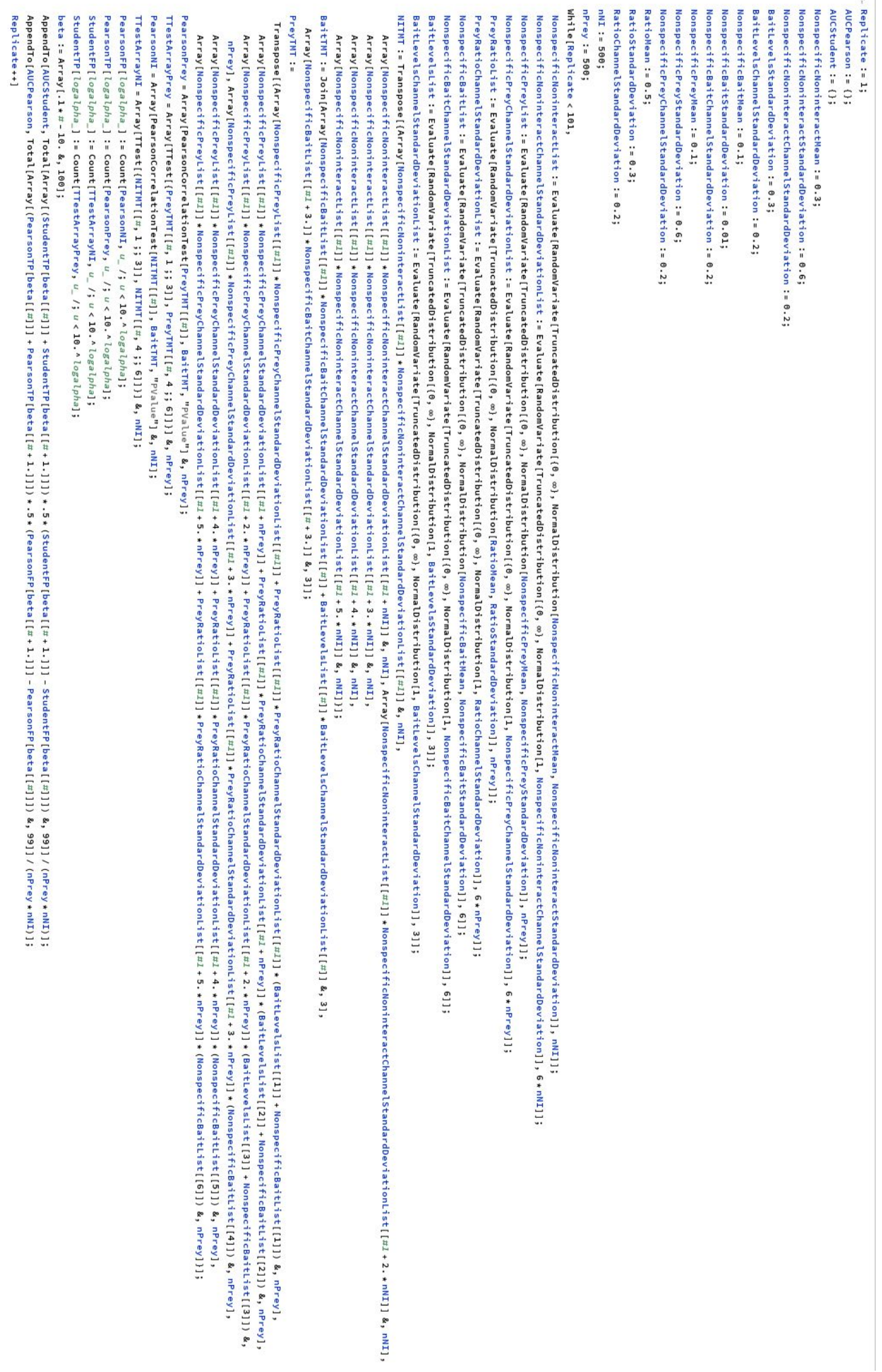




\section{SUPPLEMENTAL REFERENCES}

(1) Chatr-aryamontri, A.; Oughtred, R.; Boucher, L.; Rust, J.; Chang, C.; Kolas, N. K.; O’Donnell, L.; Oster, S.; Theesfeld, C.; Sellam, A.; et al. The BioGRID Interaction Database: 2017 Update. Nucleic Acids Research 2017, 45 (D1), D369-D379.

(2) Mellacheruvu, D.; Wright, Z.; Couzens, A. L.; Lambert, J. P.; St-Denis, N. A.; Li, T.; Miteva, Y. V.; Hauri, S.; Sardiu, M. E.; Low, T. Y.; et al. The CRAPome: A Contaminant Repository for Affinity Purification-Mass Spectrometry Data. Nature Methods 2013, 10 (8), 730-+.

(3) Budnik, B.; Levy, E.; Harmange, G.; Slavov, N. SCoPE-MS: Mass Spectrometry of Single Mammalian Cells Quantifies Proteome Heterogeneity during Cell Differentiation. Genome Biol 2018, 19 (1), 161. https://doi.org/10.1186/s13059-018-1547-5.

(4) Zecha, J.; Satpathy, S.; Kanashova, T.; Avanessian, S. C.; Kane, M. H.; Clauser, K. R.; Mertins, P.; Carr, S. A.; Kuster, B. TMT Labeling for the Masses: A Robust and Cost-Efficient, In-Solution Labeling Approach. Mol Cell Proteomics 2019, 18 (7), 1468-1478. https://doi.org/10.1074/mcp.TIR119.001385.

(5) Washburn, M. P.; Wolters, D.; Yates, J. R. Large-Scale Analysis of the Yeast Proteome by Multidimensional Protein Identification Technology. Nat Biotechnol 2001, 19 (3), 242-247. https://doi.org/10.1038/85686.

(6) Eng, J. K.; McCormack, A. L.; Yates, J. R. An Approach to Correlate Tandem Mass Spectral Data of Peptides with Amino Acid Sequences in a Protein Database. Journal of the American Society for Mass Spectrometry 1994, 5 (11), 976-989.

(7) Xu, T.; Park, S. K.; Venable, J. D.; Wohlschlegel, J. A.; Diedrich, J. K.; Cociorva, D.; Lu, B.; Liao, L.; Hewel, J.; Han, X.; et al. ProLuCID: An Improved SEQUEST-like Algorithm with Enhanced Sensitivity and Specificity. Journal of Proteomics 2015, 129, $16-24$.

(8) Tabb, D. L.; McDonald, W. H.; Yates, J. R. DTASelect and Contrast: Tools for Assembling and Comparing Protein Identifications from Shotgun Proteomics. J Proteome Res 2002, 1 (1), 21-26.

(9) Park, S. K.; Venable, J. D.; Xu, T.; Yates, J. R. A Quantitative Analysis Software Tool for Mass Spectrometry-Based Proteomics. Nat Methods 2008, 5 (4), 319-322. 